\title{
Development and Evaluation of Schematic Simulation Board for Automotive EFI System Trainer
}

\author{
Pelegren Cardino ${ }^{1}$ and Consorcio S. Namoco ${ }^{2 *}$ \\ 'Suttons Holden Arncliffe, 93 Princess Highway Arncliffe, New South Wales- 2205, Australia; \\ john.cars30@yahoo.com \\ ${ }^{2}$ College of Engineering and Architecture, University of Science and Technology of Southern Philippines, Lapasan, \\ Cagayan de Oro City- 9000, Philippines; \\ csnamocoj@yahoo.com
}

\begin{abstract}
Objectives: In this study is to evaluate the possibility of introducing innovation to the existing Electronic Fuel Injection (EFI) by developing a Schematic Simulation Board (SBB) as an additional accessory. Methods: In this innovation, a Toyota 4A-FE engine (Japan surplus) trainer is used. The schematic diagram of the EFI trainer is determined since appropriate service manual was unavailable. The SBB is then developed and integrated to the EFI trainer. Possible laboratory and learning activities are then identified based on the capabilities of the trainer. Lastly, an evaluation on the usability and acceptability on the integration of SSB to an EFI trainer is conducted based on pre-determined criteria. Findings: The enhanced trainer has a very unique design in which the laboratory set-up procedures can be accomplished with greater accuracy in less time due to its plug and unplug features. It is more presentable because the component assemblies and wiring connections are properly fitted. It can also provide consistent performance and has an easy access for maintenance and servicing in the future. With the enhanced trainer, several laboratory activities related to EFI systems can be easily undertaken. Among these are demonstration of EFI system operation, testing EFI system individual circuit components, fault simulation and troubleshooting of EFI system failure, and many other laboratory activities. From the evaluation conducted, majority of the respondents strongly agreed on the usability and acceptability of the SSB. Application/Improvements: With the SSB, it is expected that the principles and operation of EFI system can be efficiently explained and understood by an average user and can be presented and demonstrated in a simplified manner.
\end{abstract}

Keywords: Automotive Trainer, EFI System, Innovation, Laboratory Activities, Schematic Simulation Board

\section{Introduction}

Recently, the automotive industry has exerted extensive efforts in increasing the fuel efficiency of cars $^{1-7}$ as well as passengers' safety and comfort. These complex characteristics have been realized by taking advantage of the technological advancement using electronic and computer system ${ }^{8-11}$ As can be observed, recent models of automobiles are equipped with sophisticated computer and electronic system devices such as electric power steering $\frac{12}{}$, airbags, electronic-controlled transmission, anti-lock braking system (ABS), smart parking assist $\frac{13}{3}$, smart car $\frac{14}{14}$ and many others. One of the very important electronically controlled features of car is in the field of electronic fuel injection. With electronic fuel injection system, the amount of fuel entering the engine can be precisely metered, based on the driver demand and engine load at any driving condition. This helps car manufacturers in meeting the government standards in terms of fuel economy and engine emission ${ }^{6}$

With this electronic advancement in automotive technology, automotive service centers must be equipped with facilities and resources in addressing any needs and concerns

*Author for correspondence 
related to this technological trend. Due to this trend, automotive repairs had changed in emphasis from mechanical to technological work ${ }^{15}$ Vehicles use high-tech computers and complex electronic systems to monitor the performance of the vehicle. This calls for a pool of automotive service technicians who have the competence and capability in diagnosing and repairing electronic and computer-related troubles and problems of cars. $\frac{16-18}{}$ A strong sense of understanding the operation of a vehicle, including how each device interacts, as well as the ability to deal with the electronic equipment and digital reference manuals is the key to the success of a technician. Aside from the technical skills needed, proper grasp and understanding on the concepts and principles of auto-electronic system is very important. It should be pointed out that most of the existing automotive technicians do not have proper training and education in automotive electronic system since this field has not been included in their formal training until recently. Their skills are acquired through experience and constant exposure in the automotive shops ${ }^{19}$

Academic and other technical training institutions offering automotive technology are mandated to provide technical and technology graduates in automotive who will then be supplied to the demanding industries. The existence of academic institutions in the area of technology is anchored on its role as providers of human resources to answer the industrial needs in the locality, both local and global. Hence, these institutions should strive hard in its pursuit of excellence in delivering services to their clientele. Aside from excellence, academic institutions must see to it that the programs offered are relevant to the need of the industry. They must ensure that students will be armed with the relevant competencies and skills needed in industries; thus, at least the job mismatch is reduced ${ }^{20,21}$ if not eliminated. Some of the evident efforts in attaining quality and relevance in instruction are the establishment of industrial linkages ${ }^{19}$, faculty immersion in the industry and many others. In the classroom or laboratory in automotive technology, the existence of automotive instructional trainers and devices play an important role in the teaching and learning process in acquiring both technical and manipulative skills ${ }^{22,23}$

In Northern Mindanao, Philippines, there are several academic and training institutions offering automotive technology. These institutions are manned by competent faculty members and trainers and are equipped with sufficient facilities for instructional purposes in basic automotive courses. However, based on preliminary visits with these institutions and conversations with their instructors, it was found out that most of them don't have enough competitiveness in teaching electronicrelated automotive subjects particularly in the field of electronic fuel injection (EFI) system. In fact, majority of these institutions have available expensive EFI trainers but these trainers are just collecting dust in the area and appeared to be untouched. Hence, these instructional devices do not serve their purpose as far as teaching and learning are concerned. Samples of these EFI trainers are presented in Figure 1. The appearance of these trainers seems not conducive for a good learning environment. Messy and complex designs of trainers are destructive and counter-productive which will result to hesitation, frustration and resistance towards learning that will obviously affect the interests of students on learning the skills ${ }^{24}$.

Addressing the issues presented, this study is aimed to come up with an innovation to these existing messy and unfriendly EFI trainers by developing a schematic simulation board as an additional accessory. This will optimize the learning experience of the students in the field of EFI system. On the other hand, this will make the role of the instructors easier in teaching the different skills and

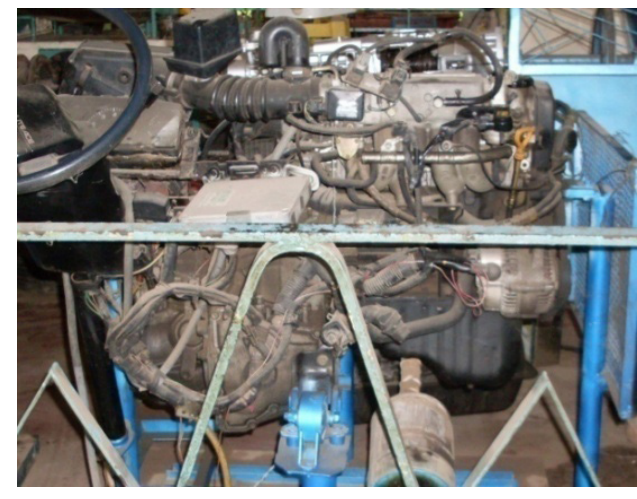

(a)

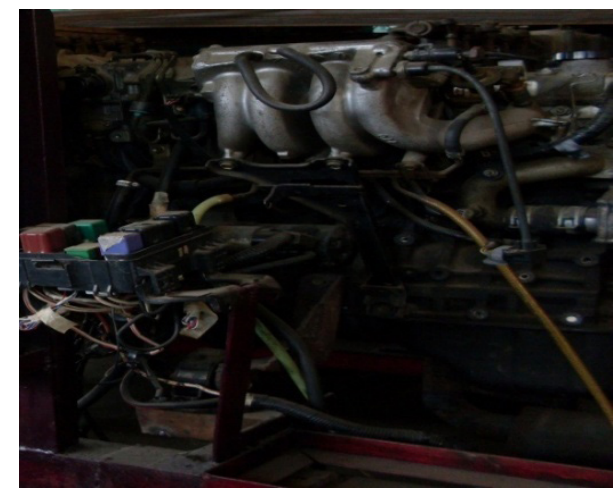

(b)

Figure 1. Samples of Existing EFI Trainers in automotive department in some training institutions in Northern Mindanao, Philippines. 
competencies in the area of EFI. In this innovation, a Toyota 4A-FE engine (Japan surplus) trainer is used where appropriate service manual is unavailable. It must be pointed out that schematic diagram specifies where the components are connected and how the circuit operates; hence, integration of the schematic simulation board will enhance the teaching and learning process. Moreover, several laboratory activities can be easily performed with the presence of the simulation board that will optimize the utilization of the instructional device. Among these are demonstration of EFI system operation, testing EFI system individual circuit components, fault simulation and troubleshooting of EFI system failure, and many other laboratory activities. Lastly, an evaluation on the usability and acceptability on the integration of SSB to an EFI trainer is also conducted based on pre-determined criteria.

\section{Materials and Methods}

\subsection{Determination of the Schematic Diagram of the EFI Trainer}

In order to extract the working schematic diagram of the existing trainer wiring, the wirings are connected based on the block diagram of the Toyota EFI system as shown in Figure 2 in order to run the engine. When wiring connections are confirmed working, a schematic diagram based on installed wiring is then drafted. This diagram is then reflected on the board, which serves as a permanent guide for the learner every time the trainer will be used. In Figure 3, a schematic diagram layout on Canvas 7.0 Software is presented.

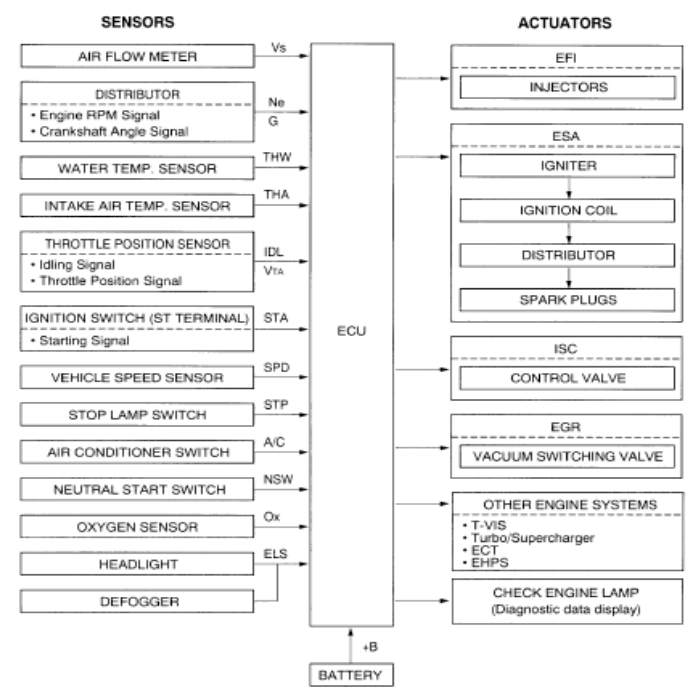

Figure 2. Block Diagram of Toyota EFI System.

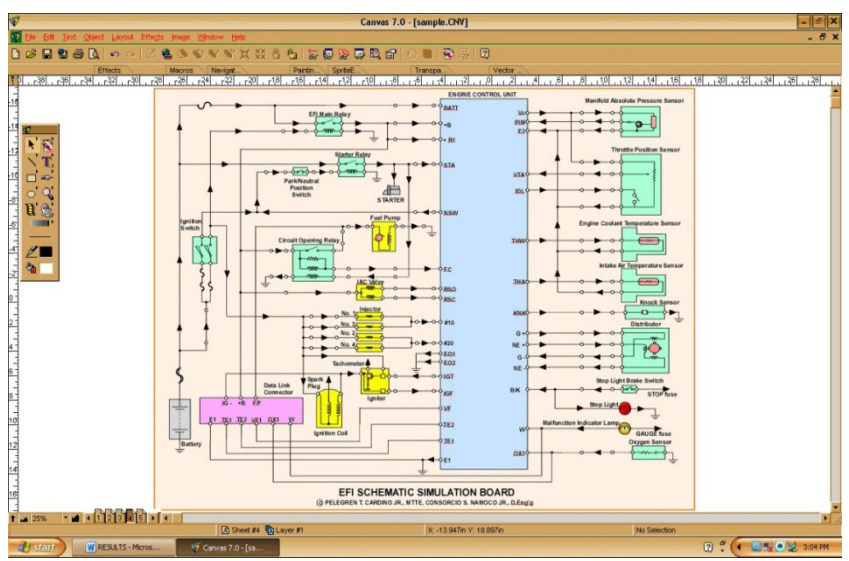

Figure 3. Schematic Diagram Layout on Canvas 7.0 Software.

\subsection{Development of the Schematic Simulation Board (SSB)}

The SSB is developed using plywood, 3 feet width and 2 feet in height. A rectangular steel frame made of $1 \times 1 \times 1 / 8$ inch angle bar serves as the attaching means of the simulation board to the electronic fuel injection system trainer. A schematic diagram of an EFI system is drawn based on current wiring connection and printed onto the tarpaulin. This is shown in Figure 4. The tarpaulin attached on the board is covered with plastic acrylic sheet for protection and at the same time for better view. Terminals and connecting points of input sensors, computers and output computers were installed with banana jack that serve as a mean for quick connection and testing of EFI components at the same time serve as the fastener of the plastic acrylic sheet and the tarpaulin integrated into the board.

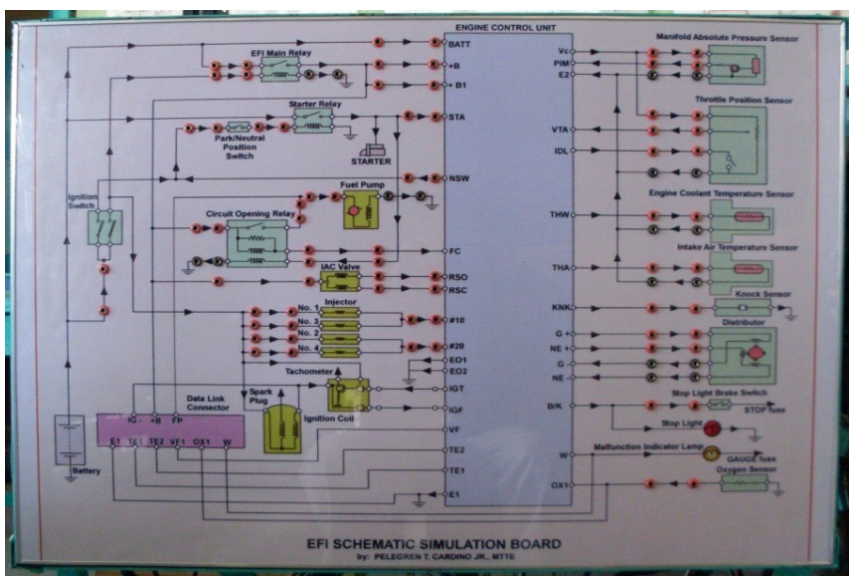

Figure 4. The Schematic Simulation Board. 


\subsection{Integration of the SSB, Testing and Fine Tuning}

The developed SSB is integrated into the EFI trainer via an attaching steel frame. The electrical wiring installed has been cut and connected to the board. The wires are soldered on the banana jack terminals at the back of the board to provide better connection. Figure 5 shows the wiring connection from the board to the engine. In Figure 6 , the SSB wiring harness and connections are shown.

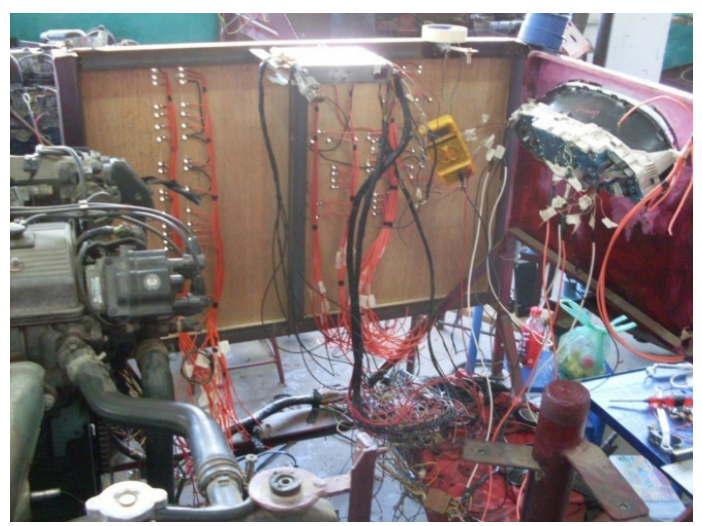

Figure 5. Wiring Connection from the Board to the Engine.

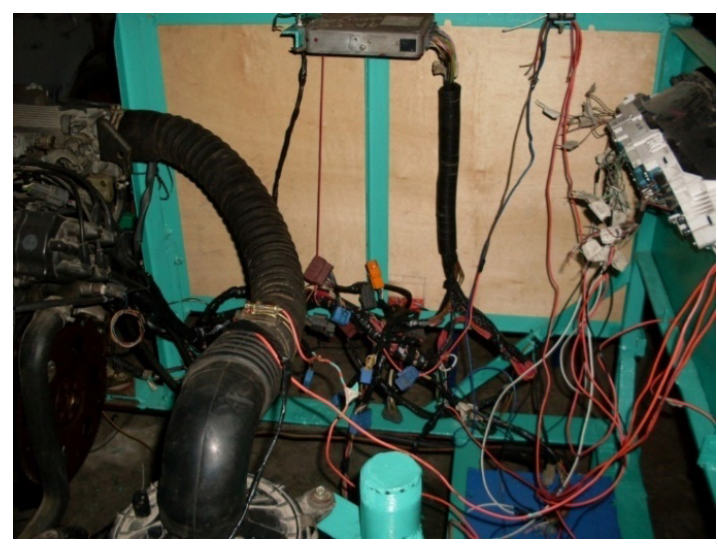

Figure 6. SSB Wiring Harness and Connectors.

\subsection{Identification of Possible Laboratory Activities}

To enhance the students' competencies, learning activities are identified based on the capabilities of the trainer. Table 1 shows some expected possible laboratory activities that can be done using the trainer.
Table 1. Some Expected Possible Laboratory Activities that can be Done Using the Trainer

\begin{tabular}{|c|c|}
\hline Topics & Activities/Competencies \\
\hline TPS Circuit & $\begin{array}{l}\text { - Connecting and Testing of TPS } \\
\text { - Voltage measurement } \\
\text { - Continuity testing of wirings }\end{array}$ \\
\hline $\begin{array}{l}\text { MAP Sensor } \\
\text { Circuit }\end{array}$ & $\begin{array}{l}\text { - Testing of MAP sensor } \\
\text { - Voltage measurement } \\
\text { - Continuity testing of wirings }\end{array}$ \\
\hline $\begin{array}{l}\text { ECU Power } \\
\text { Distribution } \\
\text { Circuit }\end{array}$ & $\begin{array}{l}\text { - Connecting and Testing of Control } \\
\text { relays } \\
\text { - Connecting ECU wirings } \\
\text { - Connecting STP and ELS signals } \\
\text { - Checking wiring connections }\end{array}$ \\
\hline Fuel Injector & $\begin{array}{l}\text { - Connecting and testing individual fuel } \\
\text { injector } \\
\text { - Voltage measurement } \\
\text { - Checking wiring connections }\end{array}$ \\
\hline $\begin{array}{l}\text { THW Sensor } \\
\text { Circuit }\end{array}$ & $\begin{array}{l}\text { - Testing THW sensor } \\
\text { - Voltage measurement } \\
\text { - Checking wiring connections } \\
\end{array}$ \\
\hline $\begin{array}{l}\text { THA sensor } \\
\text { circuit }\end{array}$ & $\begin{array}{l}\text { - Testing THA sensor } \\
\text { - Voltage measurement } \\
\text { - Checking wiring connections }\end{array}$ \\
\hline $\begin{array}{l}\text { Oxygen Sensor } \\
\text { Circuit }\end{array}$ & $\begin{array}{l}\text { - Testing OX sensor } \\
\text { - Checking wiring connections }\end{array}$ \\
\hline $\begin{array}{l}\text { Knock Sensor } \\
\text { Circuit }\end{array}$ & $\begin{array}{l}\text { - Connecting and testing of KNK sensor } \\
\text { - Checking wiring connections }\end{array}$ \\
\hline $\begin{array}{l}\text { Fuel Pump } \\
\text { Motor Circuit }\end{array}$ & $\begin{array}{l}\text { - Connecting and testing EFI Pump } \\
\text { Motor } \\
\text { - Connecting and testing Circuit Opening } \\
\text { Relay } \\
\text { - Checking wiring connections }\end{array}$ \\
\hline $\begin{array}{l}\text { Starting System } \\
\text { Circuit }\end{array}$ & $\begin{array}{l}\text { - Connecting and testing starter motor } \\
\text { - Checking and testing starter relay } \\
\text { - Connecting and testing neutral switch } \\
\text { - Checking wiring connections }\end{array}$ \\
\hline $\begin{array}{l}\text { Ignition System } \\
\text { Circuit }\end{array}$ & $\begin{array}{l}\text { - Connecting and testing ignition coil } \\
\text { - Connecting and testing igniter } \\
\text { - Checking wiring connections }\end{array}$ \\
\hline
\end{tabular}

\subsection{Evaluation on the Integration of Schematic Simulation Board on the EFI Trainer}

A research instrument is designed to evaluate the integration of SSB on the EFI trainer. The usability evaluation criteria considered are functionality, ease of use, aesthetics, reliability, maintainability/ 
serviceability, safety and flexibility. The respondents, who were automotive experts, evaluated based on the selected criteria using the Forced-Likert's scale. Descriptive statistics is used in the analysis and treatment of data.

\section{Results and Discussion}

\subsection{The Developed Schematic Simulation Board for Automotive EFI Trainer}

Figure 7 shows the Schematic Simulation Board integrated into the EFI trainer. With this innovation, several laboratory activities can be undertaken which involve connection, testing, reading of signals from sensors and actuators, troubleshooting and others of the following EFI systems circuits.

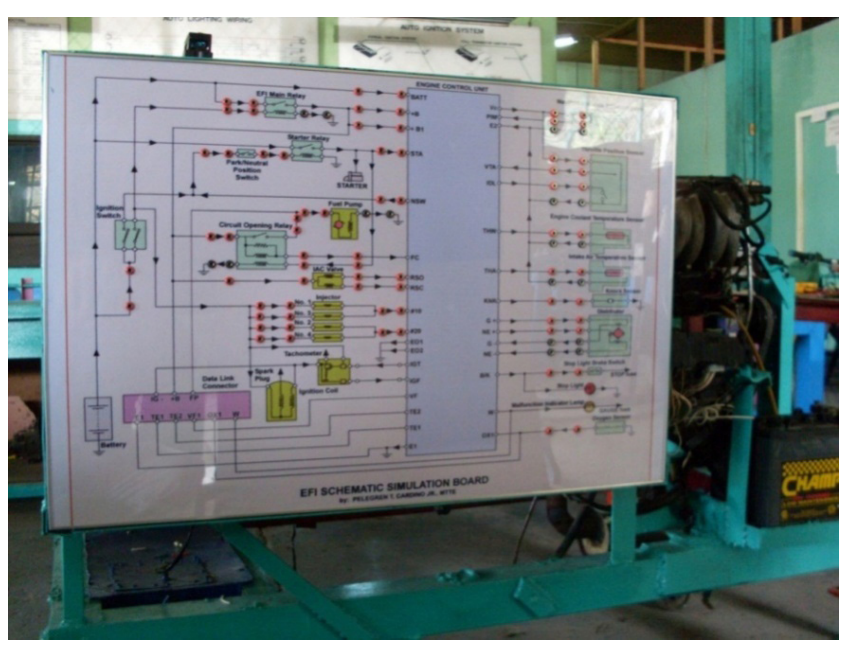

Figure 7. SSB Integrated to the Engine Trainer.

\subsubsection{Power Supply of Engine Control Unit}

The ECU has a direct battery connection (BATT) supplied from EFI fuse to maintain voltage supply for the "keep alive memory" of the ECU when the ignition switch is off. The EFI main relay $+\mathrm{B}$ output is the power source which feeds the ECU and related engine control circuits. Figure 8 shows the ECU power supply connections. In Figure 9, the ECU original wiring harness is shown.

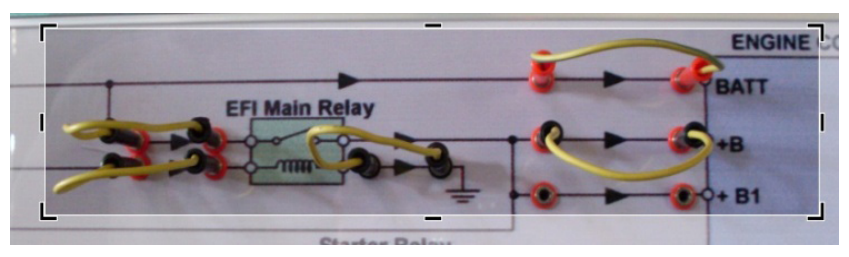

Figure 8. ECU Power Supply Connection.

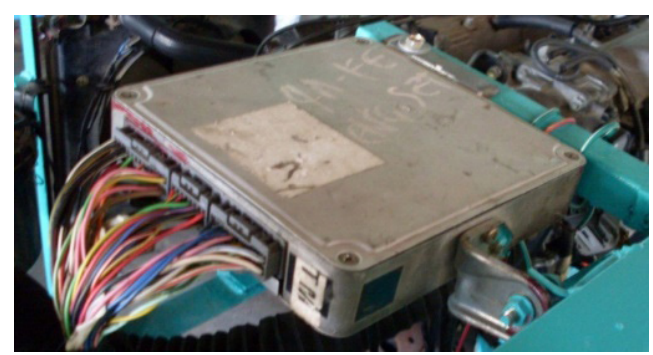

Figure 9. Engine ECU with Original Wiring Harness.

\subsubsection{Fuel Injector Circuit}

Fuel injector sprays atomized fuel into the intake manifold and is controlled by the ECU. There is one injector per cylinder mounted in the intake manifold before the intake valve. The injectors are installed with an insulator/ seal on the manifold. The fuel delivery pipe sets the injectors in place. An O-ring between the delivery pipe and injector prevents the fuel from leaking. Inside the injector is a solenoid and needle valve. To turn the injector on, the ECU turns on a transistor driver completing the voltage path to ground. The magnetic field pulls the needle valve up, overcoming spring pressure, allowing fuel to flow out from the injector. When the ECU turns off the driver circuit, spring pressure will force the needle valve onto the injector seat, shutting off fuel flow. Figure 10 shows the connection of fuel injector \#1 and \#3. Figure 11 shows the connection of fuel injector \#2 and \#4. Figure 12 shows the method of checking the resistance of individual fuel injector.

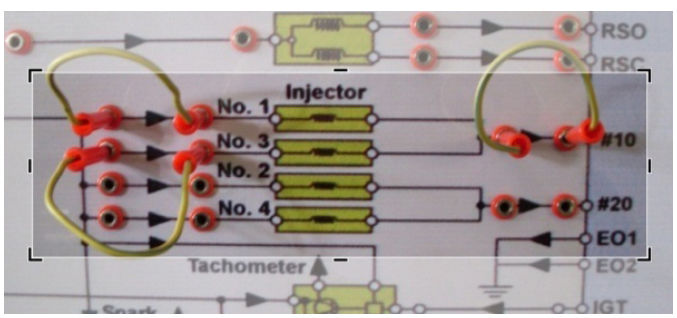

Figure 10. Injector \#1 and \#3 connection. 


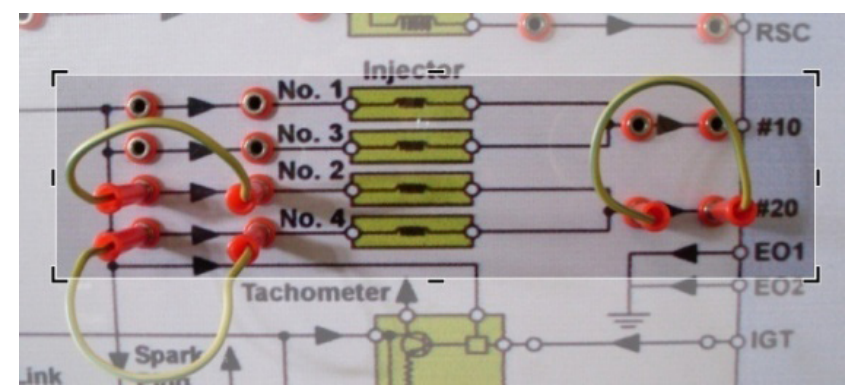

Figure 11. Injector \#2 and \#4 connection.

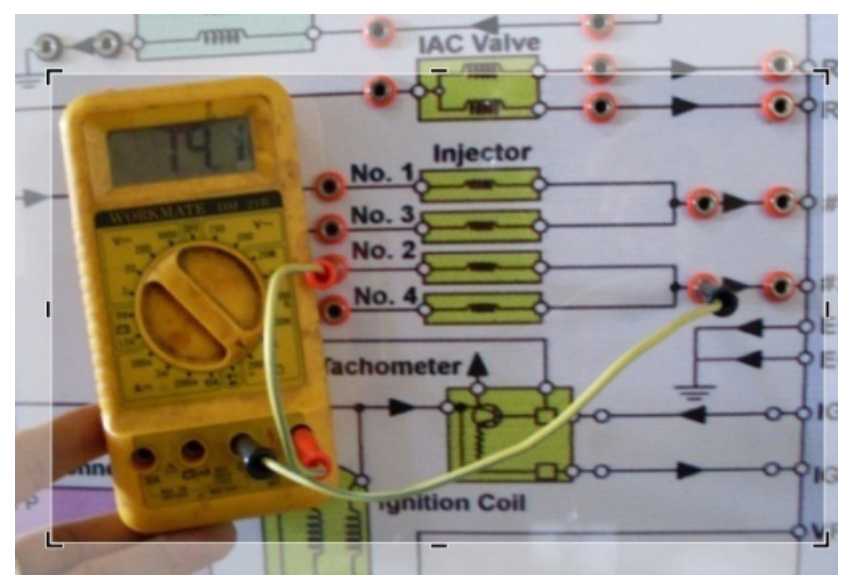

Figure 12. Fuel injector resistance check.

\subsubsection{Fuel Pump Circuit}

The fuel pump is mounted in the tank and immersed in the fuel for cooling and lubrication. When current flows through the motor, the armature and impeller rotates and draws fuel from the tank through the filter and supplies the pressurized fuel through the outlet port. Figure 13 shows the connection of fuel pump circuit while Figure 14 shows the method of checking the resistance of the fuel pump motor.

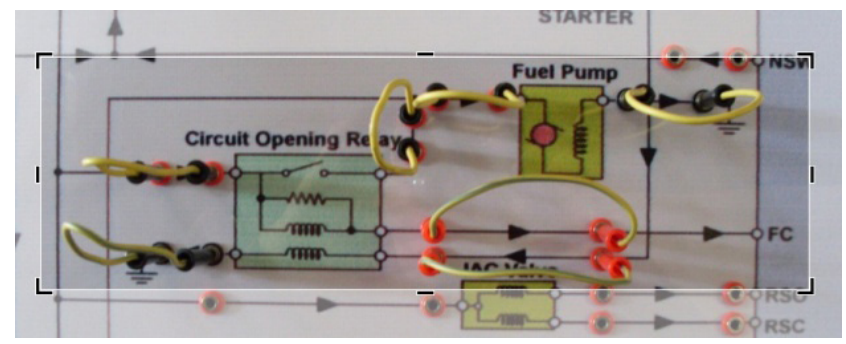

Figure 13. Fuel Pump Circuit Connection.

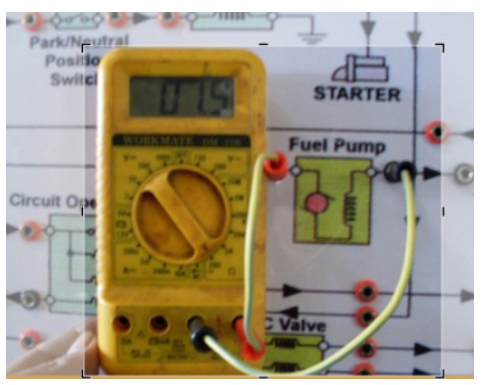

Figure 14. Fuel Pump Motor Resistance Check.

\subsubsection{Manifold Absolute Pressure (MAP) Sensor Circuit}

The sensor consists of a piezoresistive silicon chip and an integrated circuit (IC). A perfect vacuum is applied to one side of the silicon chip and manifold pressure is applied to the other side such that when intake manifold pressure changes, the silicon chip flexes causing a change in resistance. The varying resistance of the sensor causes a change in signal voltage at the Pressure Intake Manifold (PIM) terminal. Figure 15 shows the connection of manifold absolute pressure sensor.

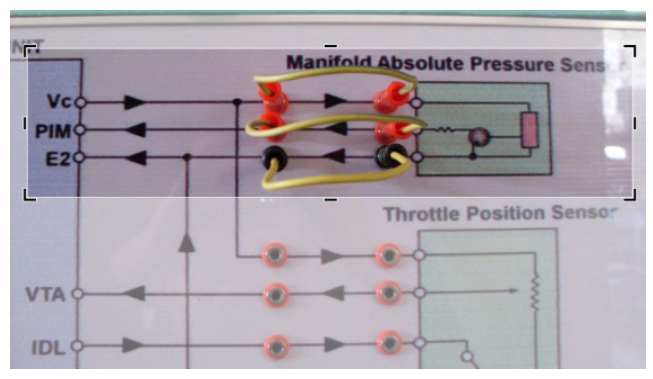

Figure 15. MAP Sensor Connection.

\subsubsection{Throttle Position Sensor (TPS) Circuit}

This engine uses TPS which is a linear type. The TPS is mounted on the throttle body. It is composed of two movable contacts, a fixed resistor and four electrical terminals (Vc, VTA, IDL and E2). As the throttle valve opens, a potentiometer circuit converts the mechanical movement of the throttle valve into a variable voltage signal. The voltage produced by this sensor is proportional to the throttle valve opening angle. At close throttle, the IDL contact is held closed, pulling the IDL signal circuit to ground. As the throttle opens, the IDL contact breaks, causing the digital IDL signal voltage to go from low to high. Figure 16 shows the connection of TP 
sensor circuit. Figure 17 shows the method of checking the TPS idle switch.

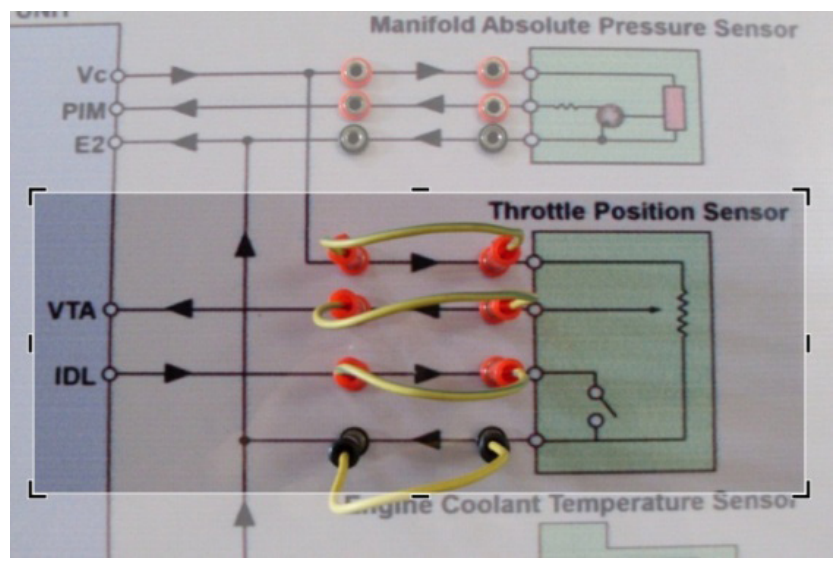

Figure 16. TP Sensor Connection.

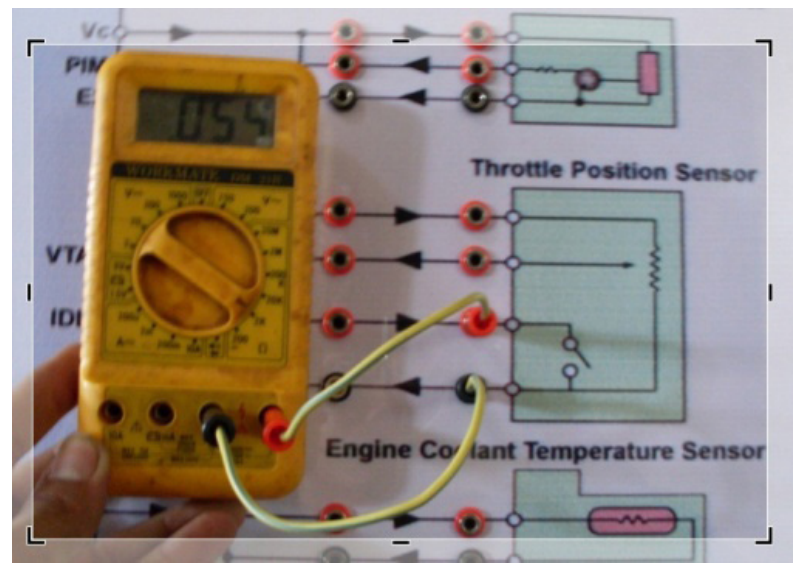

Figure 17. TPS Idle Switch Continuity Check.

\subsubsection{Engine Coolant/Water Temperature (THW) Sensor Circuit}

The THW sensor monitors the engine coolant temperature by means of internally mounted negative temperature coefficient (NTC) thermistor, whose resistance value decreases as the coolant temperature increases. This information is required because fuel vaporization is less efficient when the engine is cold. Moreover, internal engine friction also is higher during cold engine operation, increasing the operating load. The THW signal is used by the computer to determine how much fuel enrichment correction is necessary to provide good cold engine performance. Figure 18 shows the connection of ECT sensor. Figure 19 shows the method of checking the ECT sensor resistance.

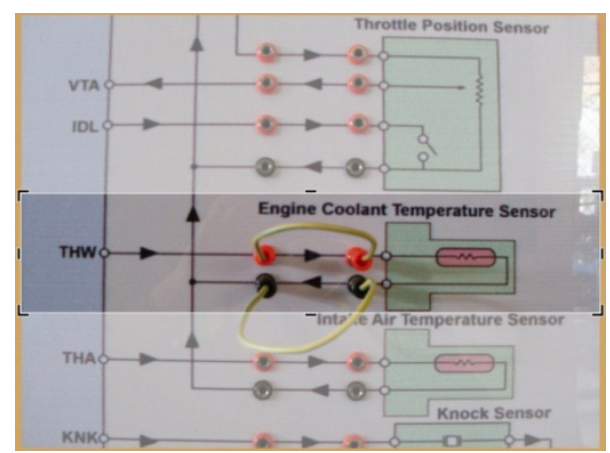

Figure 18. ECT Sensor Connection.

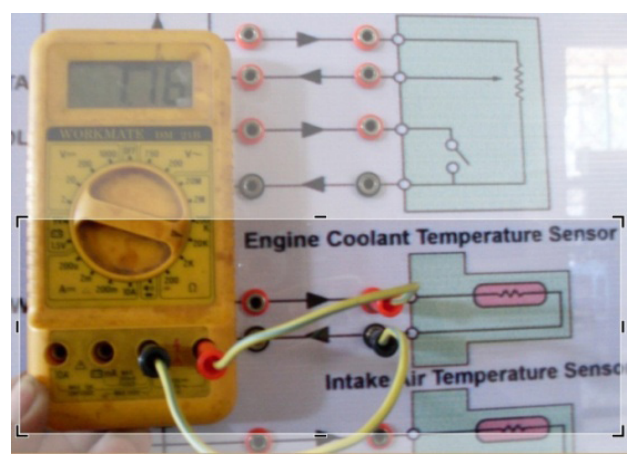

Figure 19. ECT Sensor Resistance Check.

\subsubsection{Intake Air Temperature (THA) Sensor Circuit}

The THA sensor monitors the temperature of the air entering into the intake manifold by means of thermistor. This thermistor has the same characteristics as the THW sensor. The THA signal is necessary because the pressure and density of air changes with temperature. The air is denser when cold and less dense when hot. This information is used by the computer for fuel correction purposes. Figure 20 shows the connection of IAT sensor. Figure 21 shows the method of checking the IAT sensor resistance.

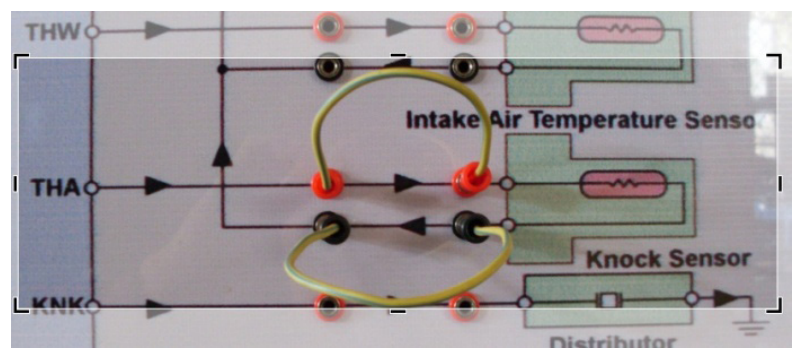

Figure 20. IAT Sensor Connection. 


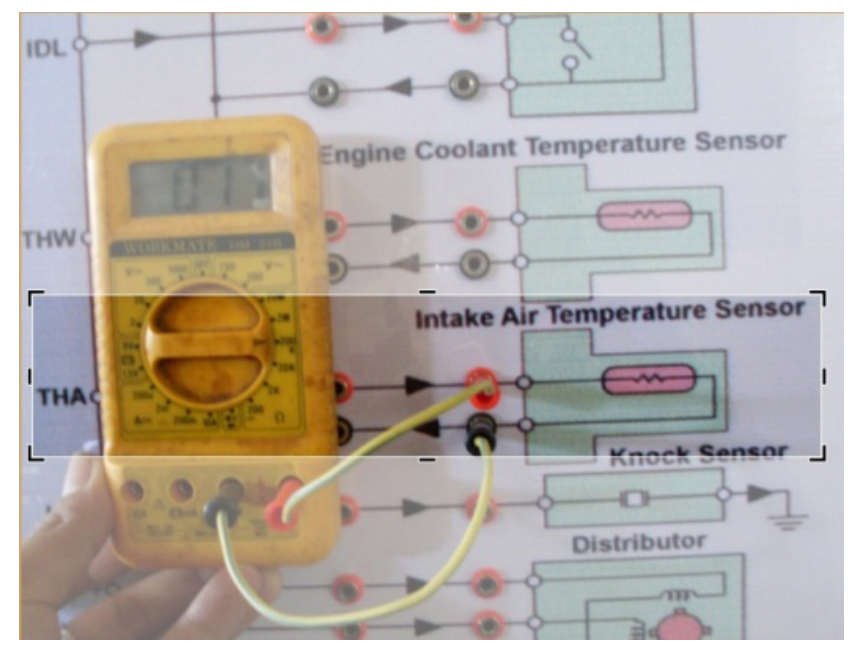

Figure 21. IAT sensor resistance check.

\subsubsection{Oxygen Sensor (OX1) Circuit}

Exhaust oxygen sensors are used to provide air/fuel ratio feedback information to the ECU. This information is used to constantly adjust the air/fuel ratio to stoichiometry during warm idle and cruise operating conditions. The efficiency of the OX1 sensor is dependent upon its operating temperature. The sensor will only generate an accurate signal when a minimum operating temperature of $750^{\circ} \mathrm{F}$ is attained. Figure 22 shows the connection of oxygen sensor.

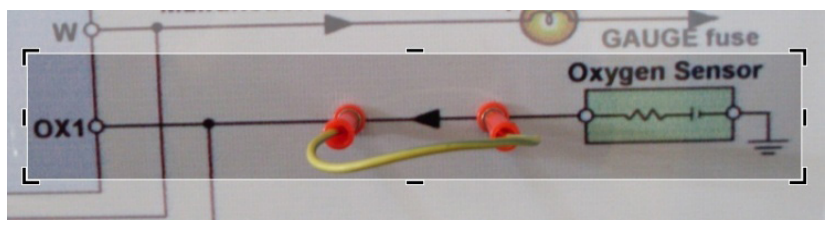

Figure 22. OX Sensor Connection.

\subsubsection{Ne (Number of engine revolutions) Sensor Circuit}

The Ne sensor consists of a pick-up coil and a toothed timing rotor. The number of teeth on the signal timing rotor is determined by the system used. The Ne sensor produces an AC waveform signal and is critical importance to the ECU. If this signal fails to reach the ECU, the engine will not run. Figure 23 shows the method of checking the Ne sensor resistance. Figure 24 shows the connection of $\mathrm{Ne}$ sensor.

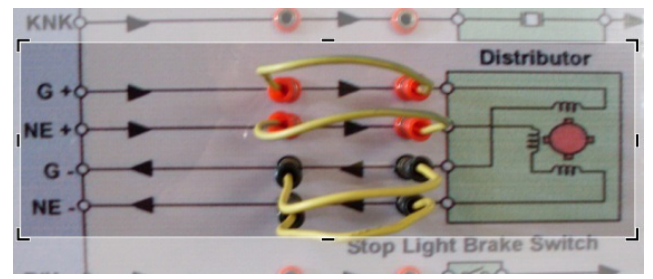

Figure 23. Ne Sensor Connection

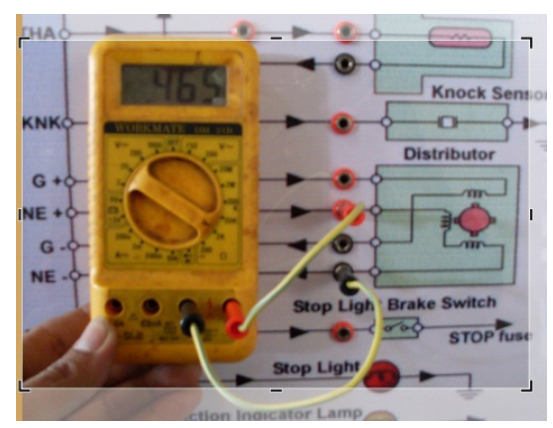

Figure 24. Ne Sensor Resistance Check.

\subsection{G Sensor Circuit}

The $\mathrm{G}$ sensor is very similar to the Ne sensor. The $\mathrm{G}$ signal represents the standard crankshaft angle and is used by the ECU to determine the ignition and injection timing in relation to Top Dead Center (TDC). Figure 25 shows the method of checking the $\mathrm{G}$ sensor.

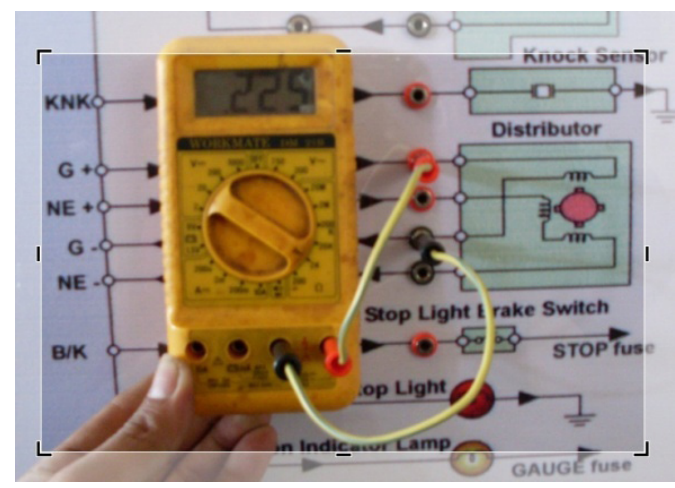

Figure 25. G Sensor Resistance Check.

\subsection{Knock (KNK) Sensor Circuit}

The KNK sensor is a piezoelectric device mounted in the engine cylinder block. The sensor will generate voltage whenever it is exposed to pressure and mechanical stress. The output voltage signal varies accordingly to the intensity of the knock. Because of other background noise and vibration, the sensor signal is filtered so it does not 
go above the pre-programmed amplitude parameters. But when the ECU judges that detonation occurs, it retards the ignition timing until the knocking stops. Timing is then advanced back to calculated value or if detonation again begins, it retarded again until the detonation stopped. Figure 26 shows the connection of KNK sensor.

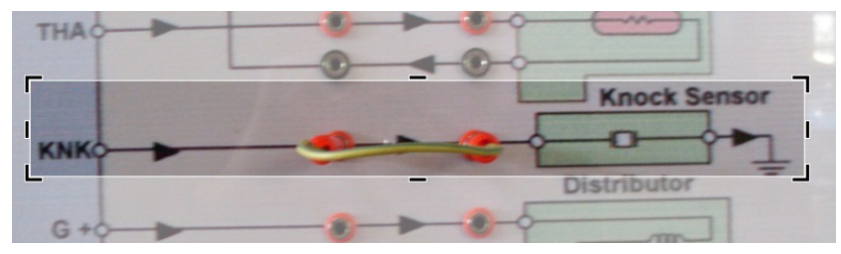

Figure 26. KNK Sensor Connection.

\subsection{Evaluation of the Usability and Acceptability of the SSB}

Evaluation on the usability and acceptabilty of the SSB are conducted. The usability evaluation criteria considered in the evaluation are functionality, ease of use, aesthetics, reliability, maintainability/ serviceability, safety and flexibility. The respondents are eleven (11) automotive experts and instructors in the university. The enhanced trainer is presented and demonstrated to the respondents after which are asked to answer the instrument based on Forced-Likert's scale (4 being highest and 1 as lowest).

Table 2. Mean Responses in terms of the Parameters Considered in Evaluating the SSB

\begin{tabular}{|l|c|}
\hline Evaluation Criteria & $\begin{array}{c}\text { Average Mean Rating } \\
\text { (4 as highest; } \text { as lowest })\end{array}$ \\
\hline Functionality & 3.87 \\
\hline Ease of Use & 3.77 \\
\hline Aesthetics & 3.83 \\
\hline Reliability & 3.63 \\
\hline $\begin{array}{l}\text { Maintainability / } \\
\text { Serviceability }\end{array}$ & 3.81 \\
\hline Safety & 3.81 \\
\hline Flexibility & 3.72 \\
\hline Acceptability & 3.93 \\
\hline
\end{tabular}

Table 2 shows the mean ratings of the evaluation of SSB based on the criteria considered. As shown in the table, the Functionality criterion has an average mean of 3.87. This implies that respondents perceived that troubleshooting exercises can be accomplished efficiently and the time to complete laboratory activities can be remarkably reduced using the proposed SSB EFI trainer as compared with that of using the actual engine. The average mean of Ease of Use is 3.77 implying that respondents strongly agree that SSB is easier to use with its plug and unplug features. In the Aesthetics criterion, the average mean is 3.83 , implying that appropriate standard symbols for component assemblies and wiring connections are used. Furthermore, the use of different colors effectively aid in presenting the three system elements such as input sensors, electronic control unit and output actuators. The Reliability criterion has an average mean of 3.63 , indicating that the SSB can provide consistent performance every time it will be put into use. For the Maintainability / Serviceability criterion, the average mean is 3.81 , showing that SSB provides easy access for maintenance / servicing of future defects. The Safety criterion has an average mean of 3.81. This implies that respondents perceived that the SSB do not pose serious risks of physical injury to users during practical exercises and at the same time reduces the risks of potential damage of EFI system components and the trainer itself. In the criterion of Flexibility, the average mean is 3.72 indicating that the SSB can be utilized to perform other function aside from the desired instructional and training purpose. The Acceptability criterion has an average mean of 3.93. This means that the respondents perceived that with the use of the SSB, life-long retention of learned knowledge and skills about EFI system can be enhanced, thus SSB is appropriate for instructional and training purposes and is highly recommended for use.

\section{Conclusion}

With the schematic simulation board, the principles and operation of EFI system can be efficiently explained and understood by an average user and can be presented and demonstrated in a simplified manner. It has a very unique design in which the laboratory set-up procedures can be accomplished with greater accuracy in less time due to its plug and unplug features. The trainer is more presentable because the component assemblies and wiring connections are properly fitted. The schematic diagram reflected on the board contains appropriate standard symbols and legible labels. The three system elements of the EFI system are effectively presented using different colors. It can also provide consistent performance and has an easy access for maintenance and servicing in the future. The trainer also reduces the risks of potential damage to its components due to its simplicity. Studies on the design and modification of EFI system circuits can be carried on 
this trainer. With the enhanced trainer, several laboratory activities related to EFI systems can be undertaken. From the evaluation conducted, majority of the respondents strongly agreed on the usability and acceptability of the SSB.

\section{References}

1. Miller WS, Zhuang L, Bottema J, Wittebrood AJ, Smet DP, Haszler A, Vieregge A. Recent development in aluminium alloys for the automotive industry. Materials Science and Engineering: A. 2000; 280(1): 37-49.

2. Hilditch TB, Souza DT, Hodgson PD. Properties and automotive applications of advanced high-strength steels (AHSS). Welding and Joining of Advanced High Strength Steels (AHSS).Amsterdam: Elsevier;2015. p. 9-28.

3. Khan LA, Mehmood AH. Cost-effective composites manufacturing processes for automotive applications. Lightweight CompositeStructuresin Transport.Amsterdam: Elsevier; 2016.p. 93-119.

4. Fuel efficiency challenges in the auto industry, http:// midwest.chicagofedblogs.org/archives/ 2009/06/fuel_efficiency.html. Date accessed: 23/ 06/ 2009.

5. Sutton M. Mercedes Outlines Road to Future. Ward's Auto World, from ABI/INFORM Global. 2010; 44(9): 21.

6. Insitu Demonstrates Electronic Fuel Injection Technology on Heavy Fuel Engine. Electronics Business Journal, from ProQuest Computing. www.businesswire.com/.../InsituDemonstrates-Electronic-Fuel-Injection-Technology, Date accessed: 10/ 1/ 2010.

7. Freescale Semiconductor; Freescale Cleans Up Small Combustion Engines with Electronic Control Solution. Journal of Transportation,23. from Academic Research Library.www.businesswire.com/.../Freescale-Cleans-SmallCombustion-Engines-Electronic-Contr..., Date accessed 26/ 8/ 2009.

8. Bailey, Paul. Geneva: , Automotive industry trends affecting component suppliers; 2005.

9. Veloso, Francisco, Kumar, Rajiv. ERD Working Paper No. 3; The Automotive Supply Chain: Global Trends And Asian Perspectives; January 2002.

10. Zuo W, Li L, Wang F, Hou X. A New Design Method of Automotive Electronic Real-time Control System. Physics Procedia. 2012; 25: 1126-32.

11. Li Pira N. Smart integrated systems and circuits using flexible organic electronics: Automotive applications. Handbook of Flexible Organic Electronics. 2015.p. 345-74.

12. Beecham M. Global market review of automotive steering systems - forecasts to 2014: 2009 edition: Technical review. Just - Auto: Global market review of automotive steering systems. ABI/INFORM Global . 2010.p. 29-43.

13. Integrated Parking Solutions, Inc; Integrated Parking Solutions, Inc. in Cooperation with NYCDOT, Parking Carma and Econolite will provide a Real-time Smart Parking Application Demonstration. Transportation Business Journal. 56. Retrieved 2010 Feb 8, from Academic Research Library.

14. Sundaram BR, Vasudevan SK, Aravind E, Karthick G, Harithaa S. 2015. Smart Car Design using RFID. Indian Journal of Science and Technology.Jun 2015; 8(11):1-5.

15. McWaters, Kimberly. The Evolution of the Automotive Service Technician - An Inside the Industry Perspective, http://www.tomorrowstechnician.com/Article/571/ the evolution_of_the_automotive_service_technician_an_ inside_the_industry_perspective_kimberly__ mcwaters. aspx; retrieved 2010 Jan 27.

16. Lang, Dan. New Skill Sets Needed for Technicians. Light \& Medium Truck, from Academic Research Library. Apr 2004; 17(3).

17. Bell, John. The new work order. Journal of Property Management. Retrieved from ABI/INFORM Global. Nov 2002; 67(6): .24-27.

18. Lang, Dan. Zen and the Art of Maintenance: Combined Skill Sets Needed in Shop. Transport Topics. Academic Research Library. Sep 2004; 3604 (S18).

19. Gaspar, Ronald N. Toyota Automotive Education Program: Enhancing TVET Qualifications and Quality Through Academe - Industry Linkage Program. 2009.

20. Weerayute S, Boonsong H. The effectiveness of Web-based Training applications in Automotive Electronic Systems. Proceedings of the IASTED International Conference. Phuket. Thailand:Web-based Education (WBE 2009); Mar 2009. p. 16 - 18.

21. Sudsomboon, Weerayute. The appropriateness of Automotive Technology Education Curricular Content through Competencies as perceived by Training Instructors. The 6th International Conference on Developing RealLife Planning Experiences: Technologies for Education. http://www.kmutt.ac.th/rippc/pdf/abs51/513002.pdf, Date accessed:2008.

22. Timpson, William M . Improve Your Teaching and Your Students' Learning. 1961.

23. oltz, Charles I. The World of Teaching Machines, Programmed Learning and Self-instructional Devices. 1961.

24. Weller, Matthew. General Principles of Motivation. Los Angeles Business Journal. Retrieved,2010 Feb. 8. 